\title{
Un caso de necrosis de la vejiga por ligadura de las hipogástricas en una operación de Werthein, con recuperación completa de la función vesical a los ocho meses de tratamiento ${ }^{(*)}$
}

\section{Doctor Aristóbulo Cruz Amaya}

Jefe del Servicio de Ginecolcgía del Hospital de San Juan de Dios de Armenia

En la operación de Wertheim para el cáncer cérvico_uterino, algunos cirujanos han empleado la ligadura de las arterias hipo. gástricas, en vez de las uterinas (1); al hacer esta ligadura, por baja que se practique, se compromete seriamente la irrigación de la vejiga, produciéndose complicaciones que pueden llegar hasta la necrosis vesical cuando la circulación colateral no se restable. ce rápidamente.

En las operaciones de Wertheim practicadas en el servicio de Ginecología del Hospital de San Juan de Dios de Armenia, se ha empleado la técnica corriente de la ligadura de las uterinas cerca de las hipogástricas; solamente en dos casos se ligaron las hi. pogástricas por debajo de la salida de las umbilicales. En esta li_ gadura, como es obvio, quedan comprendidas las vesicales infe. riores. Con esta técnica hay menos hemorragia y por lo tanto se facilita la linfadenectomía.

De los dos casos operados con esta técnica, para cáncer cérvico-uterino tipo I, el primero tuvo un post_operatorio sin com. plicaciones; no así el segundo, que es el motivo de este trabajo.

Hospital de San Juan de Dios, Armenia. Fecha de entrada: 10 de octubre de 1956. Historia número 21247. Nombre: A. T. C. de P. Procedencia: Armenia; edad: veintiocho años. Antecedentes pa_ tológicos y hereditarios sin importancia.

Antecedentes ginecológicos: menarquia a los doce años. Un aborto. Partos: 8 con hijos normales. Ultimo parto, hace 15 meses. Ciclo irregular, poli e hipermenorreas. Ultima regla el 25 de sep. tiembre de 1956.

(*) Trabajo presentado al III Congreso Colombiano de Obstetricia y Ginecología. Ibagué, 1957. 
Enfermedad actual: Hace siete años, después del segundo parto, que viene sufriendo un flujo blanco amarillento; este flu. jo se ha vuelto en los últimos meses acuoso, fétido, hemático, y el coito provoca manchas de sangre.

Examen de la enferma: Talla, 1,54; peso, 50 kilos; estado ge. neral, bueno. Cabeza y cuello nada especial. Aparato circulatorio y respiratorio, normales. Abdomen: normal. Aparato genital: Vagina amplia. Speculo: cuello con ulceración proliferante que cu. bre el labio anterior, sangra con el menor traumatismo. Flujo hemático, fétido. Prueba de Schiller: ulceración que cubre el orifi_ cio cervical y el labio anterior del cuello. Tacto vaginal: cuello de consistencia dura, sangra con el tacto; cuerpo uterino y fondos de saco normales. Tacto vagino_rectal normal.

Examen citológico del flujo vaginal: se encuentran células malignas.

Examen anatomopatológico de biopsia del cuello: carcinoma indiferenciado.

Cuadro hemático: hematies, 3.500 .000 ; leucocitos, 9.000; hemo. globina, 12 gramos $70 \%$ hematocrito; $36 \%$, valor globular 1 . Neu. trófilos: juveniles, $0 \%$; cayados, 0; segmentados, 72; eosinófilos, 2; basófilos, 0; linfocitos, 26; monocitos, 0 . Serología negativa. Tiempo de coagulación y sangría normales. Azohemia y glicemia, normales. Examen de orina, normal. Coprológico ascaris y tricocé_ ralos, ++ . Radiografía de pelvis y radioscopia pulmonar, nor. males.

El 16 de octubre de 1956 se practica operación de Wertheim (2) con ligadura de las hipogástricas por debajo de la salida de las umbilicales; sobre las ilíacas externas de ambos lados se en. cuentran ganglios hipertrofiados.

En los dos días siguientes el post_operatorio es normal, salvo una parálisis vesical. Al tercer día, la enferma acusa fuerte dolor hipogástrico, con 38 de temperatura; 108 pulsaciones; tensión, $10 \times 6$. Se aplica terramicina intravenosa. Al día siguiente apa. recen fenómenos de intoxicación y a la palpación abdominal, ade_ más de la defensa, se encuentra crepitación en la región infraum. bilical.

Al sexto día de post_operatorio se reopera. Al cortar las sutu. ras de la pared abdominal se' encuentran los tejidos edematiza. dos y debajo la vejiga de paredes verdosas que se desgarran sin sangrar con cualquier manipulación. Se intenta el cierre de los puntos que empiezan a fistulizarse; se coloca una sonda vesical a permanencia y un Pen_Rose para el drenaje de la herida abdo. 
minal. En los días siguientes el estado general mejora y la orina se hace normal. A los 7 días, en vista de la mejoría, se retira la sonda, después de lo cual hace una micción normal; pero por la tarde empieza a salir orina por la herida abdominal y por la vagi. na. En los días siguientes so presenta una pielitis que se trata con tetraciclina y se empieza a preparar para nueva intervención.

El 20 de noviembre de 1956 se hace nueva laparotomía con el ánimo de practicar una uretero_enteroanastomosis; en la explora. ción de la vejiga se encuentran dos grandes zonas circulares con ausencia completa de pared vesical, con rebordes gruesos y acar. tonados que al avivarlos sangran; entonces se decide el cierre de esos dos enormes orificios, en varios planos, se coloca sonda vesi. cal a permanencia y drenes en la pared abdominal. En los días subsiguientes se trata con vitaminas y aminoácidos y se controla durante un mes; al cabo de este tiempo y en vista de que la orina es normal y ha desaparecido completamente la fístula abdominal se retira la sonda y por la tarde del mismo día aparece de nuevo la fístula abdominal y al dia siguiente la vaginal, lo que demuestra la dehiscencia de las suturas vesicales. Se coloca nueva_ mente sonda a permanencia y la enferma sale del hospital para se. guir bajo control durante tres meses. En este tiempo se presetan varios accesos de pielitis; se trata con antibióticos, vitaminas y aminoácidos. Se retira la sonda y la enferma continúa haciendo micciones normales. Al cabo de un mes de retirada la sonda regre. sa al hospital con fenómenos de cistitis aguda, vuelve a aparecer la fístula abdominal; al pasarle sonda vesical sale una orina espe. sa, turbia, con tejidos esfacelados. Se coloca sonda a permanencia y se trata con antibióticos e instilaciones vesicales desin. fectantes.

El 16 de abril de 1957 se inicia tratamiento con instilaciones vesicales de nitrato de plata en solución al $1 \mid 2.000$ (3); este tratamiento se continúa durante dos meses y medio con soluciones cada vez más concentradas, hasta llegar al 1/100.

El 1o. de julio de 1957 se retira la sonda; las instilaciones se siguen efectuando cada 8 días, la enferma orina perfectamente bien y en estas condiciones ha continuado.

El 16 de octubre de 1957, un año después de practicada la operación de Wertheim, la enferma se encuentra en perfectas condiciones; no se observa ningún signo de reproducción o metástasis tumoral y su vejiga sigue funcionando normalmente. 
Examen cistoscópico practicado el 30 de noviembre de 1957:

"Meato uretral normal. Orina vesical, limpia. Capacidad ve. sical, 200 c. c. Medio vesical limpio. Mucosa: muy escasa, conges. tión del trígono, de tipo banal. En la parte media del piso se en. cuentra una formación poliposa, redonda, pequeña y cuya mu. cosa es de color gris. Hacia la parte porterior de la cúpula ve. sical se observan zonas cicatricales, constituídas por estrías grue. sas en sentido diagonal. El resto de la mucosa es color rosado claro, intercalando pequeñas zonas blanquecinas de aspecto cica. tricial. Los meatos ureterales son de aspecto normal, pero la eya. culación no se aprecia, seguramente por fibrosis de sus contornos."

Resumen y conclusiones.-Se presenta un caso de necrosis vesical como consecuencia de la ligadura de las arterias hipogástricas en una operación de Wertheim. Se describe su evolución y tratamiento hasta la recuperación completa.

Ante la posibilidad de esta complicación no es aconsejable esta técnica, y en caso de fístulas vesicales, de cualquier magnitud, un tratamiento fácil y efectivo consiste en la sonda a per. manencia $o$ instilaciones vesicales con soluciones de nitrato de plata en concentraciones ascendentes.

\section{BIBLIOGRAFIA}

1 R. PROUST.-Cirugía del aparato genital de la mujer.

2. SIEGFRIED T'APFER.-Operación radical de Wertheim.

3. WHARTON L.-Ginecología, incluyendo urología fєmenina. 